\title{
Effect of Boundary Layer and Rotor Speed on Broadband Noise from Wind Turbines
}

\author{
Vasishta Bhargava ${ }^{1, *}$, Rahul Samala²
}

Bhargava V iD https://orcid.org/0000-0001-5990-0650

Samala R iD https: / / orcid.org/0000-0002-6163-8556

\author{
How to cite
}

Bhargava V; Samala R (2019) Effect of Boundary Layer and Rotor Speed on Broadband Noise from Wind Turbines. J Aerosp Technol Manag, 11: e2619. https://doi.org/10.5028/jatm.v11.1045

\begin{abstract}
Trailing edge surface of aerofoil is an important source of broadband aerodynamic noise production. In this paper, three aerofoil self-noise mechanisms from turbulent boundary layer near trailing edge surface are studied. Numerical computations were performed for a three bladed $2 \mathrm{MW}$ horizontal axis upwind turbine of blade length $37 \mathrm{~m}$ and source height of $80 \mathrm{~m}$, for wind speeds of 8-15 m/s. A weighted 1/3 ${ }^{\text {rd }}$ octave band sound power levels (SPL) are evaluated for receiver located at distance of total turbine height and at $2 \mathrm{~m}$ above ground. The results obtained for sound power level using baseline models showed maximum values occurring between $300 \mathrm{~Hz}$ and $1 \mathrm{kHz}$ region of spectrum. The trends for BPM model showed a reduction of $\sim 2 \mathrm{dBA}$ near $1 \mathrm{kHz}$ region of spectrum at $10 \mathrm{~m} / \mathrm{s}$, but Grosveld's and Lowson model were identical and agreed over the entire spectrum. The effect of rotational speed on sound power levels using three baseline models are illustrated at a wind speed of $8 \mathrm{~m} / \mathrm{s}$ for $2 \mathrm{MW}$ turbine. Results showed that for a change of $\pm 10 \%$ rotor speed from the rated value, there is an increase of 2 to $6 \mathrm{dBA}$ over the entire sound spectrum due to differences in blade tip speed.
\end{abstract}

KEYWORDS: Boundary layer, Wind turbine, Sound power, Rotor speed, Blade.

\section{INTRODUCTION}

Sound is composed of mechanical waves that are produced when hydrodynamic pressure fluctuations in fluid vary above or below the reference atmospheric pressure values ( $20 \mu \mathrm{Pa}$ for air). It results in noise when this pressure amplitude exceeds the human hearing response and cause effects like sleep disturbances or annoyance (O'Neal et al. 2009). For free field and unbounded flows, these pressure disturbances depend on velocity fluctuations that convect along free stream direction of flow. However, in diffuse sound field the aerodynamic sound production becomes significant when the turbulent boundary layer flow interacts with the fixed or moving surfaces such as an aerofoil, flat plate or corrugated geometry undergoing edge scattering (Doolan et al. 2012; Fink 1979).

For a wind turbine, noise production from mechanical equipment is not critical (Son et al. 2009). Instead, the dominant noise mechanism results from rotating blades due to boundary layer near the trailing edge surface of an aerofoil that varies with flow conditions. Another important factor responsible for noise production is rotational speed of turbine. For subsonic flows, aerodynamic noise produced from moving blades exhibits tonal and broadband character. The broadband nature is due to scattering of incident turbulence field or random velocity fluctuations in flow field, and tonal nature from blade passing frequency or its multiples. Further, it has been found from several experiment studies that most of noise occurs during the downward motion of blade and radiates in symmetrical manner with respect to the chord line (Moriarty and Migliore 2003; Oerlemans 2011; Schepers et al. 2007).

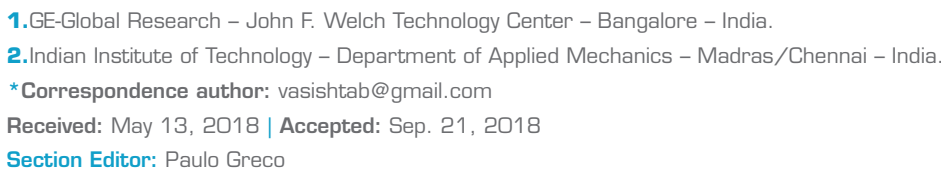


In this work, empirical trailing edge noise models proposed by Brooks et al. (1989) (BPM), Grosveld (1985) for broadband noise prediction are numerically evaluated for different flow and operating conditions for a $2 \mathrm{MW}$ horizontal axis wind turbine of blade length $37 \mathrm{~m}$ at $0^{\circ}$ downwind position. Inputs to simulation consist of geometric and aerodynamic data for given blade and the pitch angle of blade is set to $3.2^{\circ}$. In the analysis of sound pressure level, for each model, $2 \mathrm{D}$ incompressible quasi-uniform flow was assumed along blade span. Blade elements are considered as point source and boundary element momentum method was used to calculate aerodynamic data (Hansen et al. 2008). For prediction of single source sound power level, octave band attenuation due to geometric divergence, also known as spherical spreading, is taken into account ignoring other factors due to atmospheric absorption, ground surface impedance and barrier or screen effects. A-weighted filter corrections were used since it is most suitable to filter the low-mid frequency range of sound spectrum (Bastasch 2011).

\section{METHODS}

\section{BPM (BROOKS, POPE, MAROCOLINI) MODEL -TBL-TEN}

Brooks et al. (1989) derived this model using data from wind tunnel experiments with NACA0012 aerofoil with varying chord lengths in anechoic chamber to measure sound pressure levels. The turbulent boundary layer noise occurs due to suction and pressure sides of aerofoil and is considered as common source of noise from wind turbine blade. Aerofoil is assumed as half-infinite flat plate. The thickness of turbulent boundary layer $(\delta)$, local Mach number $(M)$, length of blade segment $(L)$, as well as the distance between the observer and source $\left(r_{e}\right)$ are important parameters to predict the acoustic field from 2D lifting surfaces (Brooks et al. 1989; Amiet and Schlinker 1981). Equations 1 and 2 are used to calculate the sound pressure levels involving spectral functions, while Eq. 3 is used for angle dependent noise source, which is caused at moderate to high angle of attack (AOA) (Brooks et al. 1989; Zhu et al. 2005; Moriarty and Migliore 2003; Dijkstra 2015). Noise is produced due to interaction of turbulent boundary layer with trailing edge surface of an aerofoil for an incident hydrodynamic pressure field. This causes local pressure in flow higher than atmospheric pressure, resulting in sound. The sound pressure levels are therefore obtained by adding all the components logarithmically for each blade section and given by Eq. 4 :

$$
\begin{aligned}
& \mathrm{SPL}_{\mathrm{p}}=10 \cdot \log 10\left[\frac{\delta_{\mathrm{p}}^{*} \mathrm{M}^{5} \mathrm{~L} \overline{\mathrm{D}_{\mathrm{h}}}}{\mathrm{r}_{\mathrm{e}}^{2}}\right]+\mathrm{A}\left[\frac{\mathrm{St}_{\mathrm{p}}}{\mathrm{St_{1 }}}\right]+[\mathrm{K} 1-3]+\Delta \mathrm{K} 1 \\
& \mathrm{SPL}_{\mathrm{s}}=10 \cdot \log 10\left[\frac{\delta_{S}^{*} \mathrm{M}^{5} \mathrm{~L} \overline{\mathrm{D}_{\mathrm{h}}}}{\mathrm{r}_{\mathrm{e}}^{2}}\right]+\mathrm{A}\left[\frac{\mathrm{St}_{\mathrm{s}}}{\mathrm{St}_{1}}\right]+[\mathrm{K} 1-3] \\
& \mathrm{SPL}_{\alpha}=10 \cdot \log 10\left[\frac{\delta_{\mathrm{s}}^{*} \mathrm{M}^{5} \mathrm{~L} \overline{\mathrm{D}_{\mathrm{h}}}}{\mathrm{r}_{\mathrm{e}}^{2}}\right]+\mathrm{B}\left[\frac{\mathrm{St}_{\mathrm{s}}}{\mathrm{St}_{2}}\right]+\mathrm{K} 2 \\
& \mathrm{SPL}_{\text {Total }}=10 \cdot \log 10\left[10^{\frac{\mathrm{SPL}_{\alpha}}{10}}+10^{\frac{\mathrm{SPL}_{\mathrm{p}}}{10}}+10^{\frac{\mathrm{SPL}_{\mathrm{s}}}{10}}\right]
\end{aligned}
$$

The Strouhal number $(S t)$ is used for describing oscillating flows, which involve center frequency as well as characteristic dimension of source. For flow over aerofoil it is calculated using pressure and suction side displacement thickness, given by Eq. 5:

$$
\mathrm{SPL}_{\mathrm{Total}}=10 \cdot \log 10\left[10^{\frac{\mathrm{SPL}_{\alpha}}{10}}+10^{\frac{\mathrm{SPL}_{\mathrm{p}}}{10}}+10^{\frac{\mathrm{SPL}_{\mathrm{S}}}{10}}\right]
$$

It can be seen that $S t_{1}$ is related to turbulent boundary layer trailing edge noise and varies with free stream velocity $(U)$ and Mach number $(M)$, while $S t_{2}$ is related to separation noise in spectra (Grosveld 1985; Zhu et al. 2005). These parameters are set between 0.01 and 10 for low Mach number flows and vary along span direction. The Reynolds number expresses the relation between inertial and viscous forces in flow, measured along the chord direction of blade, given by Eq. 6. This parameter is function of pressure side displacement thickness and also chord length of aerofoil for calculating level adjustment function, $\Delta \mathrm{K} 1$, and amplitude functions, K1 and K2 respectively. For wind turbines the blade experiences moderate to high Reynolds number (Re) 
of order, Re from $3.5 \times 10^{6}$ to $1.2 \times 10^{7}$ flows and vary along the blade span. This type of source uses high and low frequency directivity functions, given by Eq. 7 :

$$
\begin{gathered}
\operatorname{Re}_{p}=\left[\frac{\delta_{p}^{*} U}{\vartheta}\right] ; R e_{c}=\left[\frac{U c}{\vartheta}\right] ; \\
\mathrm{D}_{\mathrm{h}}(\theta, \emptyset)=\frac{2 \sin ^{2}\left(\frac{1}{2} \theta\right) \sin ^{2}(\emptyset)}{(1+\mathrm{M} \cos \theta) \cdot\left(1+\left(\mathrm{M}-\mathrm{M}_{\mathrm{C}}\right) \cos \theta\right)^{2}} ; \mathrm{D}_{\mathrm{L}}(\theta, \emptyset)=\frac{\sin ^{2}(\theta) \sin ^{2}(\emptyset)}{(1+\mathrm{M} \cos \theta)^{4}}
\end{gathered}
$$

The boundary layer thickness $(\delta)$ and displacement thickness $\left(\delta^{*}\right)$ are calculated as function of the chord length of aerofoil (c) and angle of attack (AOA) for both pressure and suction sides of aerofoil, as given in Brooks et al. (1989). For all components of this source, the acoustic pressure produced near trailing edge varies as fifth power of Mach number dependence or $M^{5}$ and exhibits broadband characteristics. Further, for low Mach number flows, $M \sim 0.2$, noise radiated from pressure and suction sides of aerofoil depend upon the spectral functions A and B, which are correlated with the aerodynamic and boundary layer properties (Brooks et al. 1989; Grosveld 1985; Lee and Lee 2013; Moriarty and Migliore 2003). The spectral function $A$ is related to turbulent boundary layer-trailing edge noise and function $B$ with flow separation noise. For non-compact sources and attached flows, high frequency directivity function $\left(D_{h}\right)$ is used and given by $\sin ^{2}(\theta / 2)$. The combined Doppler shift and convective amplification terms use $(1+M \cos \theta)\left[1+\left(M-M_{c} \cos \theta\right)\right]^{2}$ show a cardioid pattern of sound field near trailing edge. For stalled or fully separated flow on blade, the trailing edge noise source reduces to complex dipole pattern and becomes a function of $M^{6}$. Therefore, for such case, angles of attack usually exceed $12.5^{\circ}$ for which low frequency directivity, $D_{L}$ is also used. The directivity angles, $\theta$ and $\varnothing$, are aligned in the azimuth and polar directions of rotor plane for turbine and shown by coordinate reference system in ref (Brooks et al. 1989; Grosveld 1985; Moriarty and Migliore 2003).

\section{GROSVELD MODEL - TBL-TEN}

In this model, noise is produced due to turbulent boundary layer attached to trailing edge surface of an aerofoil. It is similar to BPM model and based on scaling law prediction for trailing edge noise spectrum (Grosveld 1985). Since a wind turbine blade is tapered and twisted, the individual blade segments of length $(l)$, encounter different local free stream velocities and experience unsteady blade lift and drag forces. However, this model assumes linearly tapered rotor and ignores twist, hence does account for corrections in the angle of attack over individual blade segments as in the case of BPM. For uniform 2D lifting flows, the trailing edge noise for an isolated aerofoil can be approached with Eq. 8 (Grosveld 1985; Zidan et al. 2014):

$$
\mathrm{SPL}_{\text {total }}=10 \cdot \log 10\left[\frac{B \delta \mathrm{U}^{5} \mathrm{~L} \overline{D_{\mathrm{h}}}}{\mathrm{r}_{\mathrm{e}}^{2}} \cdot K K_{2}\right]+C
$$

where $K K_{2}$ is the frequency dependent scaling function, given by Eq. 9:

$$
\mathrm{KK} 2(\mathrm{f})=10 \cdot \log 10\left[\left\{\left(\frac{\mathrm{St} \prime}{\mathrm{St}_{\max }}\right)^{4}\right\}\left[\left(\frac{\mathrm{St} \prime}{\mathrm{st}_{\max }}\right)^{1.5}+0.5\right]^{-4}\right]
$$

where $S t_{\max }$ is the peak Strouhal number set to $\sim 0.1$; and $S t^{\prime}$ is the Strouhal number as function of boundary layer thickness $-\delta$; $B$ is the number of blades; and $U$ is the free stream velocity scaled to $U^{5}$, Empirical constant $C-5.44 \mathrm{~dB}$.

Grosveld (1985) model uses the directivity function $\left(D_{h}\right)$ proposed by Fink (1979), which is similar to Eq. 7. For turbulent flows, the thickness and displacement thickness of turbulent boundary layer for aerofoils are approached using the empirical curve fitting function dependent on chord length (c) of aerofoil and angle of attack (AOA) and given by Eqs. 23 and 33 in Grosveld (1985). It must be noted that no blades for a wind turbine determine the rotor solidity. Hence this model also considers the rotor solidity factor in order to estimate the sound pressure level from a turbine. The Doppler shift and convective amplification term as discussed in BPM model is set equal to 0.8 times the Mach number to include the effects of dipole radiation of sound along the blade chord (Grosveld 1985; Schepers et al. 2007). 
The overall $1 / 3^{\text {rd }}$ octave band far field sound pressure level is obtained by logarithmic integration of individual contributions of blade elements for each blade.

\section{LOWSON MODEL - TBL-TEN}

In this model, the far field sound pressure level is predicted based on empirical equations similar to BPM method; however, the directional nature of sound is ignored (Brooks et al. 1989; Zidan et al. 2014). Sound pressure calculation involves the spectral function $G_{6}$, which depends on the Strouhal number, Mach number, boundary layer thickness, distance between source and receiver, as well as empirical constant. The empirical constant changes according to flow turbulence and evaluated using mathematical gamma function. The frequency dependent scaling factors are also used to determine the sound pressure level, given by Eqs. 10 and 11 :

$$
\begin{gathered}
\mathrm{SPL}_{\text {total }}=10 . \log 10\left[\frac{\delta \mathrm{M}^{5} \mathrm{~L}}{\mathrm{r}_{\mathrm{e}}^{2}} \cdot G_{6}(f)\right]+128.5 \\
G_{6}(\mathrm{f})=\frac{4\left(\frac{f}{f_{\max }}\right)^{2.5}}{\left[\left(\frac{f}{f_{\max }}\right)^{2.5}+1\right]^{2}}
\end{gathered}
$$

where $f_{\max }$ is dependent on free stream Mach number $M$ and boundary layer thickness $\delta$. The boundary layer thickness is also approximated according to the Eqs. 23 and 33 given in Grosveld (1985). L-span segment length $\left(r_{e}\right)$ is the distance between the source and receiver, in $\mathrm{m}$.

Figure 1a shows the illustration of the major noise generation mechanism from a wind turbine blade. It has been known that flow along blade chord is predominantly turbulent during turbine operation. The turbulent flow remains non-uniform along the blade span and varies with turbulence integral length scale, turbulence intensity level; Therefore trailing edge noise levels are found to vary with the thickness of turbulence boundary layer as well as the slope of trailing edge surfaces. Figure $1 \mathrm{~b}$ shows

(a)

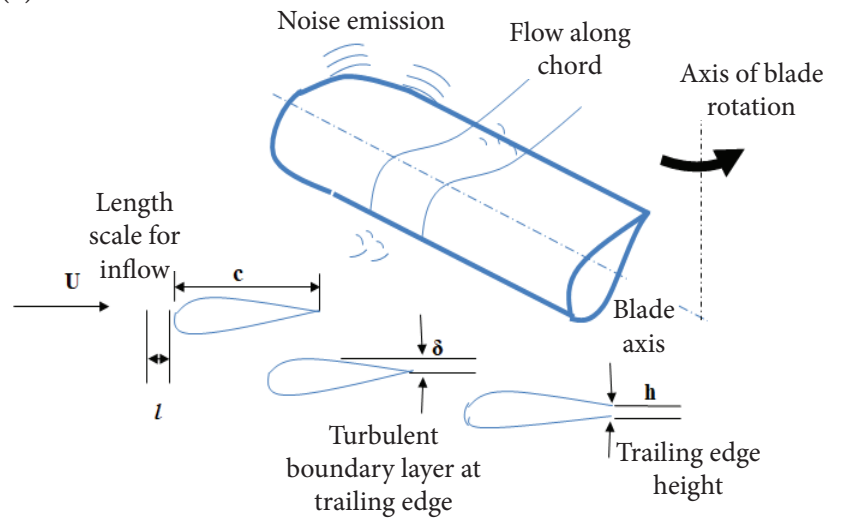

(b)

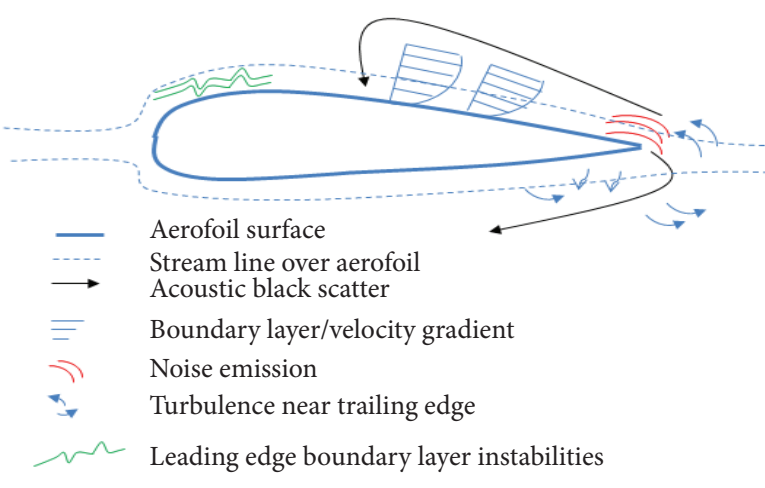

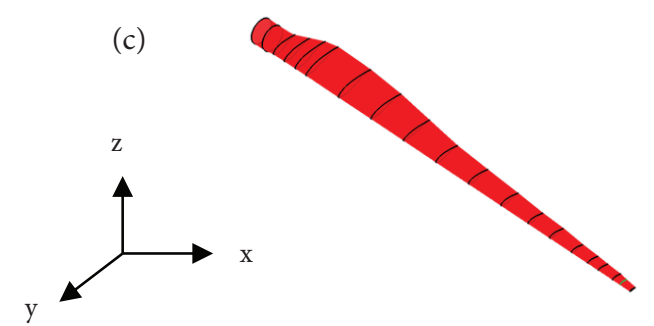

Figure 1. (a) Schematic of major noise mechanisms from wind turbine blade, adapted from (Grosveld 1985; Doolan et al. 2012); (b) noise generation mechanism near the trailing edge of aerofoil; (c) illustration of a 37 m turbine blade developed using NuMAD software. 
streamlined flow over aerofoil surface. Near the trailing edge of aerofoil, the acoustic waves are emitted normal to chord line and caused due to interaction of turbulent boundary layer with aerofoils surface (Dijkstra 2015; Oerlemans et al. 2007; Oerlemans 2011; Schepers et al. 2007). A feedback mechanism can also be observed between the emitted acoustic waves and the incoming flow at leading edge to cause instabilities which propagate downstream along the chord. It must be noted that for all three trailing edge noise models, the boundary layer thickness or displacement thickness is essential for predicting the overall sound pressure levels. Figure 1c shows the $37 \mathrm{~m}$ blade developed using NuMAD software using the blade geometric properties twist and chord length. The maximum twist and chord length of each blade for the present work is $13^{\circ}$ and $3.22 \mathrm{~m}$ respectively.

\section{RESULTS AND DISCUSSION}

In the analysis of turbulent boundary layer trailing edge noise, 2D incompressible flow over aerofoil surface was assumed. The programs for three models were implemented in MATLAB 2017b software and numerical simulation performed on 12GB RAM Intel core $158^{\text {th }}$ gen computing environment. For each wind speed, the clock time for computation took $\sim 3 / 4$ h. Minimum three aerofoils, NACA 0012, NACA 63215 and NACA 6320 were chosen to approximate the entire blade shape. The values for intermediate aerofoils have been linearly interpolated along the blade span. Boundary layer data for each aerofoil was obtained using XFOIL computations. It can be seen from Fig. 2a that at constant wind speed of $10 \mathrm{~m} / \mathrm{s}$ the BPM model predicts peak sound power level of $\sim 90 \mathrm{dBA}$ near $800 \mathrm{~Hz}$ in frequency spectra; while for Grosveld shows a peak near low frequency region of spectra $200 \mathrm{~Hz}$ with a $\sim 80 \mathrm{dBA}$ when displacement thickness $\left(\delta^{\star}\right)$ is considered. However, pressure amplitudes for Grosveld's model are found to agree more closely with those predicted from BPM when thickness $(\delta)$ is considered. Similar trends can be observed for Lowson's model, in which the directivity function is ignored in prediction of sound pressure level.

Figure $2 \mathrm{~b}$ shows the difference in amplitudes across the spectra due to boundary layer thickness and displacement thickness parameters. A minimum difference of $7.5 \mathrm{dBA}$ can be seen for whole spectrum and step change is observed for all three models near $1 \mathrm{kHz}$ equal to $8.5 \mathrm{dBA}$. From Figs. $3 \mathrm{a}$ and $3 \mathrm{~b}$, results for computed $1 / 3^{\text {rd }}$ octave A-weighted frequency spectra for BPM, Lowson and Grosveld baseline models at wind speeds of $8 \mathrm{~m} / \mathrm{s}$ and $10 \mathrm{~m} / \mathrm{s}$ were validated using experiment data obtained for GE 1.5sle and Siemens SWT-2.3MW turbines. It must be noted that a penalty up to $10 \mathrm{~dB}$ consisting of wind shear and tone was added to simulated results due to the fact that experiment results take account up to $5 \mathrm{~dB}$ tonal penalty and miscellaneous effects (O’Neal et al. 2009). Good correlation between experiment data and Lowson model has been observed for $100 \mathrm{~Hz}$ and $1 \mathrm{kHz}$ region, while data agrees closely within $5 \mathrm{dBA}$ with respect to BPM and Grosveld between $1 \mathrm{kHz}$ and $2 \mathrm{kHz}$ region of spectrum. Further, the difference in low frequency region can be caused due to other noise mechanisms such as inflow turbulence, which are taken into account during field measurements. Figures $4 \mathrm{a}, 4 \mathrm{~b}$ and $4 \mathrm{c}$ show the contour plot of frequency spectra for BPM,

(a)

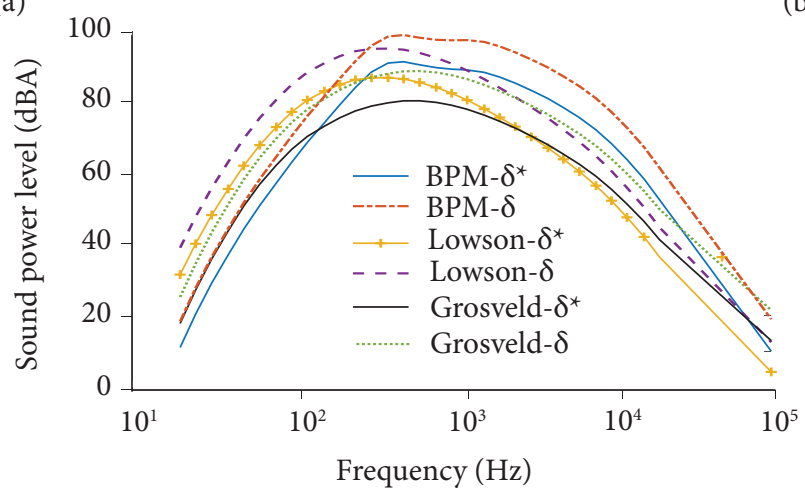

(b)

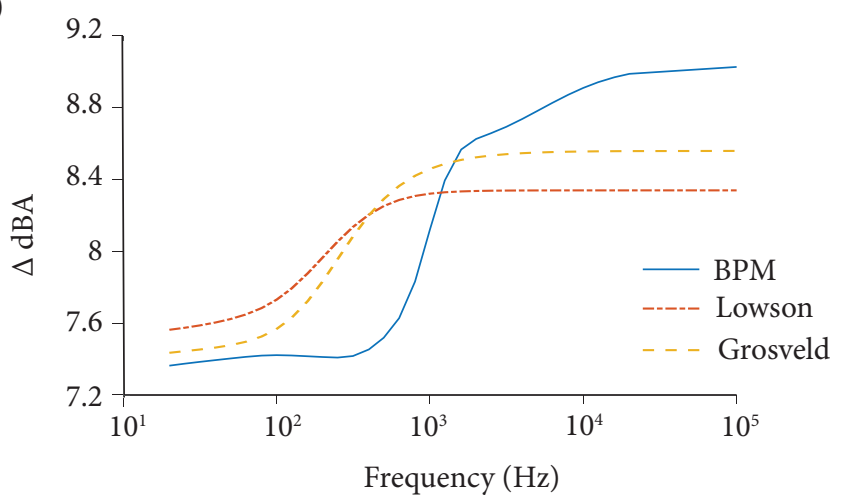

Figure 2. (a) Comparison of frequency spectra of TBL-TE, A-weighted sound power level using BPM, Grosveld and Lowson models at free stream velocity, $U=10 \mathrm{~m} / \mathrm{s}$; (b) $\triangle \mathrm{dBA}$, between thickness $\boldsymbol{\delta}$, displacement thickness $\boldsymbol{\delta}^{\star}$ at free stream velocity, $U=10 \mathrm{~m} / \mathrm{s}$, receiver height of $2 \mathrm{~m}$ and at distance of $\sim 120 \mathrm{~m}$, i.e. total turbine height $(H \mathrm{H}+\mathrm{D} / 2)$. 
Grosveld and Lowson baseline TBL-TEN models discussed before. The SPL levels are plotted with varying wind speeds, between $8 \mathrm{~m} / \mathrm{s}$ to $15 \mathrm{~m} / \mathrm{s}$ and between $20 \mathrm{~Hz}$ to $3.15 \mathrm{kHz}$ region of spectrum. The amplitude of power spectra is found to reach peak values of $100 \mathrm{dBA}$ and $107 \mathrm{dBA}$ near $500 \mathrm{~Hz}$ for all three models.

It can be noted that the A-weighted apparent sound power level can be evaluated based on the equivalent continuous sound pressure level for a receiver located in far field and given by Eq. 12:

$$
L_{w A}=L_{A e q}+10 \log 10\left[\frac{4 \pi R^{2}}{S_{0}}\right]-6
$$

The second term in Eq. 12 represents the geometric divergence of sound waves. $R$ is the slant distance from hub height of turbine to the receiver location; $S_{0}$ is the reference area, $1 \mathrm{~m}^{2} ; L_{\text {Aeq }}$ is the far field equivalent continuous A-weighted sound pressure level evaluated using the noise prediction methods discussed earlier.

(a)

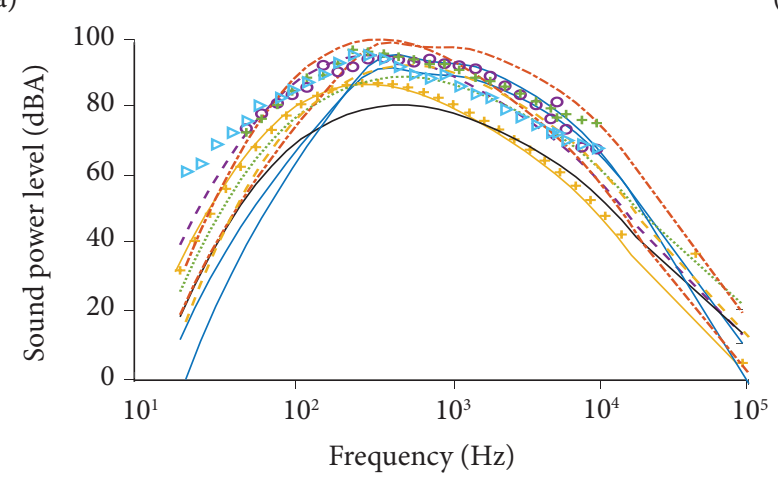

(b)

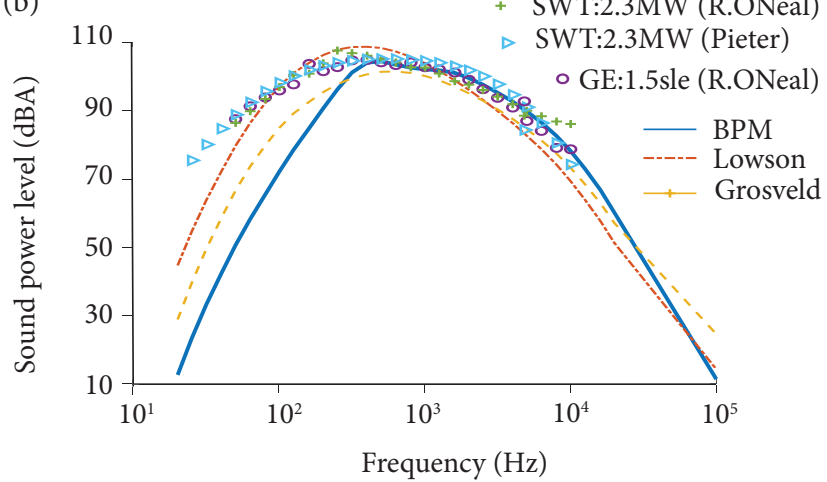

Figure 3. Validation of BPM, Grosveld and Lowson baseline models with OASPL experiment results of Dijkstra (2015) and O'Neal et al. (2009) for 2.3 MW turbine and GE 1.5sle turbine (O'Neal et al. 2009) (a) at wind speed of $8 \mathrm{~m} / \mathrm{s}$, receiver height of $\sim 2 \mathrm{~m}$ located at $120 \mathrm{~m}$ from turbine; (b) at wind speed of $10 \mathrm{~m} / \mathrm{s}$, receiver height of $\sim 2 \mathrm{~m}$ located at $120 \mathrm{~m}$ from turbine.

From Fig. 4a, it is evident that the sound power levels (SPL) increase with free stream velocities $(U)$ between 8 and $15 \mathrm{~m} / \mathrm{s}$ at constant rotational speed of 15 RPM. The maximum values are obtained for Lowson model, which range between 100 and $107 \mathrm{dBA}$ and agree closely with those obtained from Grosveld's model. However, sound power level from BPM agrees closer with Grosveld's model predictions than with Lowson's model between $2 \mathrm{kHz}$ and $3 \mathrm{kHz}$, as depicted in the Figs. $4 \mathrm{a}$ and $4 \mathrm{c}$. For all the cases, the SPL values are considered when the observer is in downwind or $0^{\circ}$ position. In Fig. 5a all the baseline TBL-TEN models are compared with increasing rotational speed of 14, 15 and 17 RPM, respectively. The influence of rotational speed can be seen higher near $500 \mathrm{~Hz}$ region. For frequencies $f<100 \mathrm{~Hz}$, a difference of $10 \mathrm{dBA}$ can be observed for each model. The level change at each frequency in spectrum is shown in Fig. 5b. A change of $3 \mathrm{dBA}$ was found for BPM's and Lowson's models, while for Grosveld's model it is $\sim 2 \mathrm{dBA}$. A step change can also be seen near $1 \mathrm{kHz}$ region for BPM's and Lowson's models while for Grosveld's model it is observed near $100 \mathrm{~Hz}$. For each of models, the peak is found to occur near $1 \mathrm{kHz}$, caused by turbulent boundary layer interaction from suction side of aerofoils; while for BPM's model a secondary peak can also be seen between $1 \mathrm{kHz}$ and $2 \mathrm{kHz}$, caused by turbulent boundary layer from the pressure side (Oerlemans et al. 2007; Schepers et al. 2007). Hence, model sensitivity on account of varying boundary layer parameters and rotor speed are demonstrated well. Fig 6a shows the orientation of the observer at $60^{\circ}$ and $240^{\circ}$ positions with respect to the rotor azimuth of machine. The maximum differences in sound power levels are computed numerically for those positions and for downward moving blade azimuth locations using one single blade element located at $75 \% \mathrm{r} / \mathrm{R}$. The results in Fig. $6 \mathrm{~b}$ show that peak difference of $\sim 10 \mathrm{dBA}$ is observed between $80^{\circ}$ and $170^{\circ}$ blade azimuth angle during downward motion and from outboard sections of blade. This can be attributed to increasing relative velocity field over blade span during downward motion. 
(a)

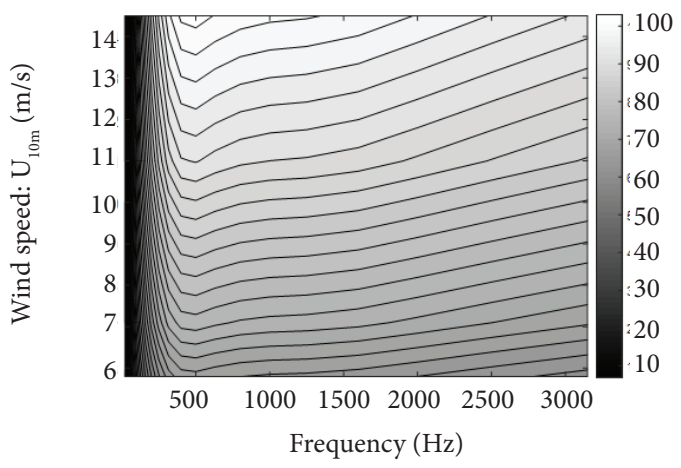

(b)
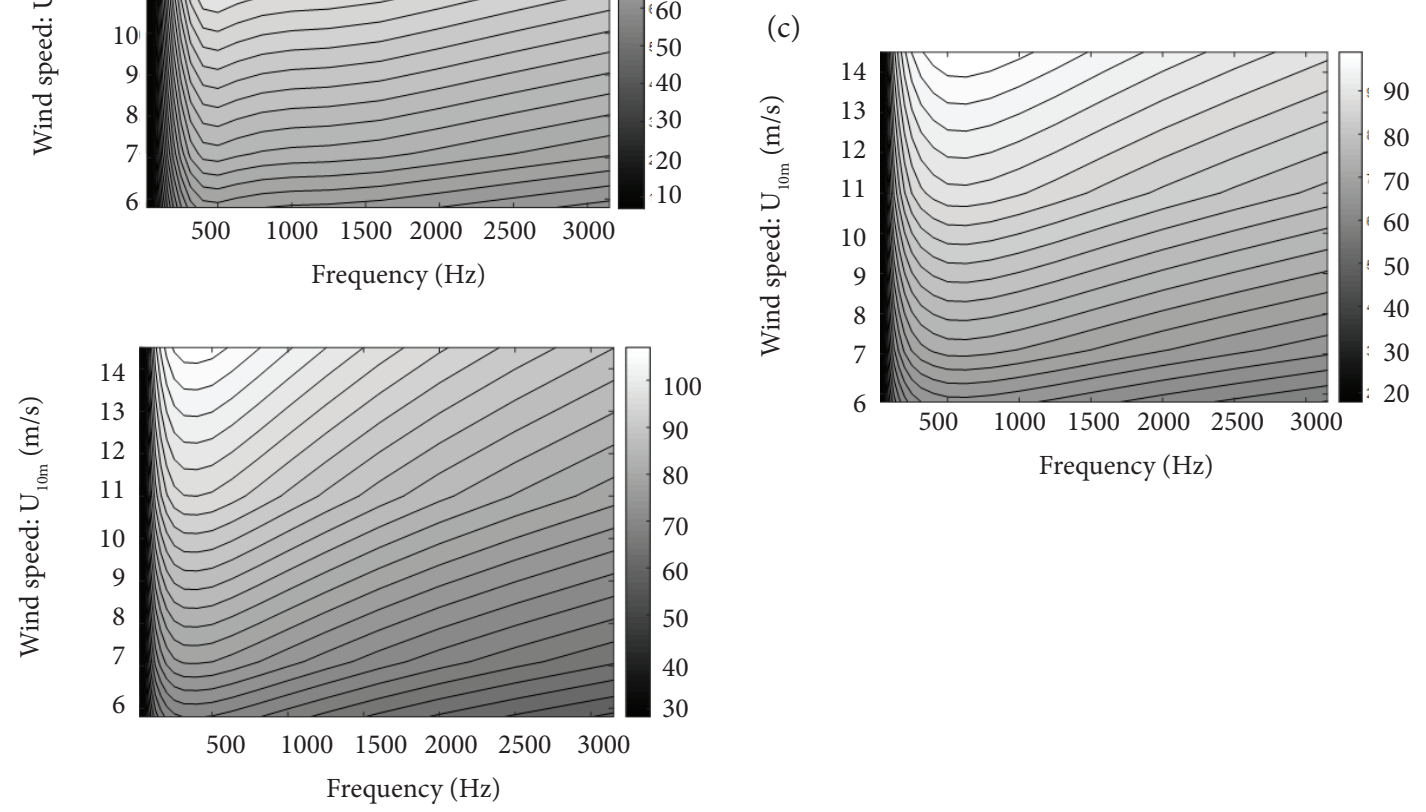

Figure 4. Illustration of TBL-TE contours, Sound Power Level (dBA) prediction from (a) BPM; (b) Lowson; and (c) Grosveld baseline models at fixed rotor speed of 15 RPM for wind speeds 8-15 m/s, receiver height of $2 \mathrm{~m}$, at distance of $\sim 120 \mathrm{~m}$, i.e. total turbine height $(\mathrm{HH}+\mathrm{D} / 2)$.
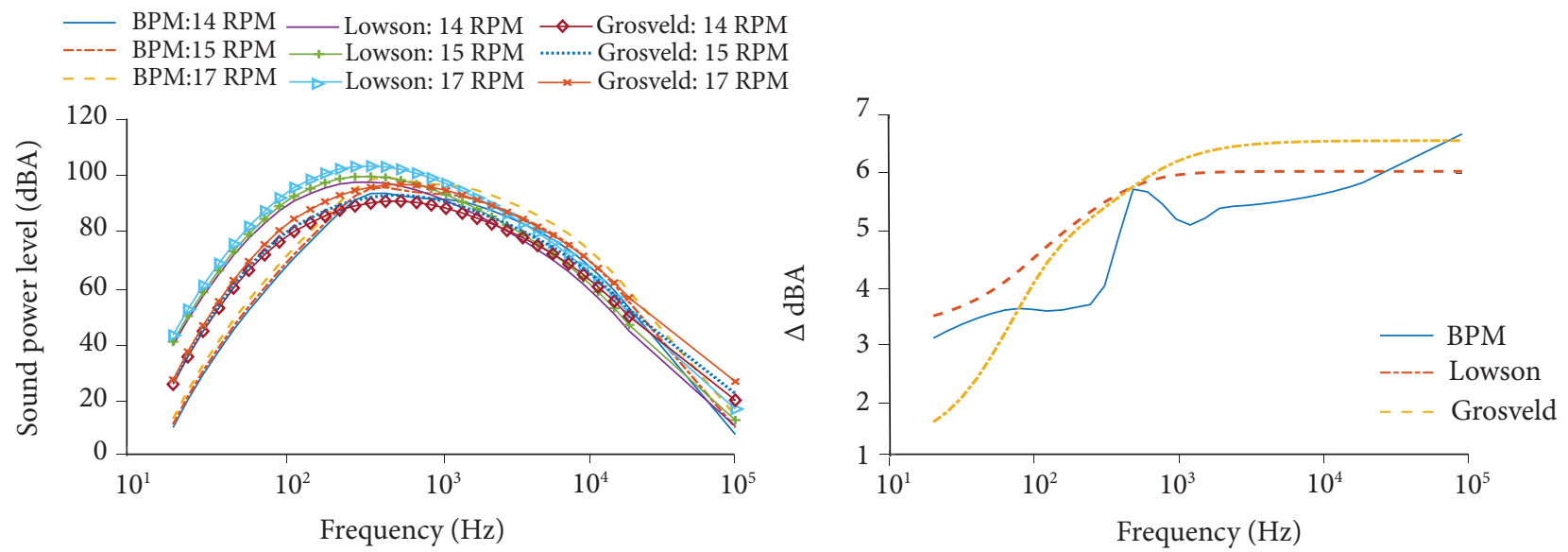

Figure 5. Frequency spectra of BPM, Grosveld and Lowson baseline models at wind speed of $8 \mathrm{~m} / \mathrm{s}$, receiver height of $2 \mathrm{~m}$, located at distance of $120 \mathrm{~m}$ (a) for 14, 15 and 17 RPM; (b) $\triangle \mathrm{dBA}$, between 14 and $17 \mathrm{RPM}$ for baseline models.

Further, the influence of receiver heights on perceived noise levels $\left(L_{w A}\right)$, is also evaluated for $2 \mathrm{MW}$ turbine. From Table 1 it can be seen that a constant difference of $\sim 0.3 \mathrm{~dB}$ is obtained between $63 \mathrm{~Hz}$ and $8 \mathrm{kHz}$ for both BPM and Grosveld methods when the receiver is shifted from $10 \mathrm{~m}$ to $2 \mathrm{~m}$ height above ground level. However, this trend is not seen for Lowson's method and increase of $\sim 0.1 \mathrm{~dB}$ in sound power level is found when the receiver location is at $2 \mathrm{~m}$ above ground level. It must be noted that for all simulation runs, distance between source and receiver and source heights are kept constant and in accordance with IEC-61400-11 regulations for measurement of acoustic emissions from wind turbines. Hence the receiver height difference exhibits negligible 
change in computed sound power levels for constant operating conditions of the turbine. However, it is not known clearly whether receiver height difference affects the measured data of sound power levels given the same operating conditions of the mach

(a)

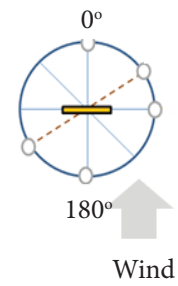

From above

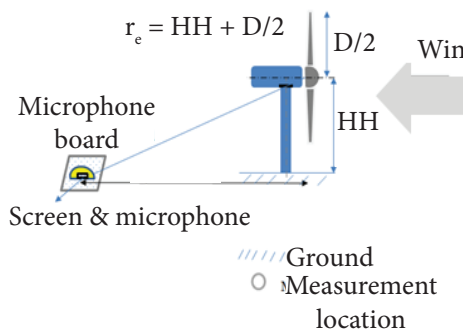

From side

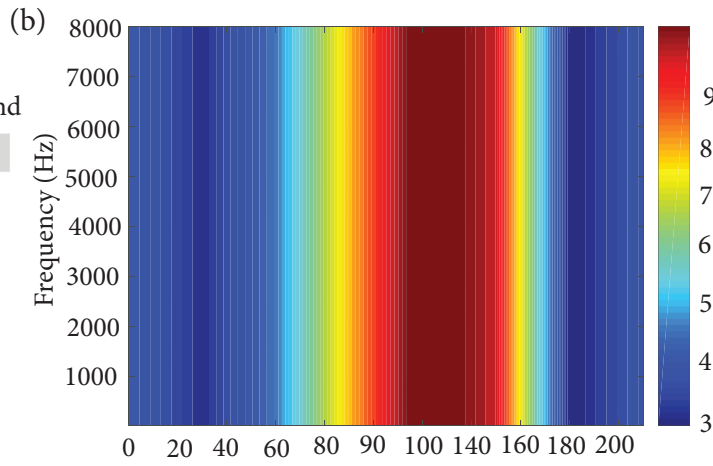

Blade azimuth angle (deg)

Figure 6. (a) Illustration of plan and side views of observer azimuth position and distance of receiver location from turbine according to IEC61400-11 standards. Horizontal bar represents the rotor plane and dashed line across rotor plane shows location of $60^{\circ}$ and $240^{\circ}$ observer positions; (b) difference in sound power level $\left(\triangle \mathrm{dBA}\right.$ ) between $60^{\circ}$ and $240^{\circ}$ observer positions for an isolated blade element 75\% R of single blade using BPM model at fixed speed of 15 RPM, at a wind speed 8 m/s for 2 MW turbine.

Table 1. Comparison of $1 / 3^{\text {rd }}$ octave A-weighted sound power level for trailing edge noise source of a $2 \mathrm{MW}$ turbine due to change in receiver height from $10 \mathrm{~m}$ to $2 \mathrm{~m}$ between $63 \mathrm{~Hz}$ and $8 \mathrm{kHz}$ using BPM, Grosveld and Lowson method. Receivers are located at $~ 120 \mathrm{~m}$ and downwind position, for both cases at wind speed of $8 \mathrm{~m} / \mathrm{s}$ and at 15 RPM.

\begin{tabular}{|c|c|c|c|c|c|c|c|c|c|c|}
\hline Parameter & \multicolumn{10}{|c|}{ BPM } \\
\hline Frequency $(\mathrm{Hz})$ & 63 & 100 & 200 & 400 & 800 & 1000 & 2000 & 4000 & 5000 & 8000 \\
\hline Receiver height $(10 \mathrm{~m})$ & 73.57 & 78.41 & 84.50 & 89.83 & 92.85 & 92.34 & 87.92 & 82.50 & 80.56 & 76.01 \\
\hline Receiver height $(2 \mathrm{~m})$ & 73.28 & 78.12 & 84.21 & 89.54 & 92.57 & 92.06 & 87.64 & 82.21 & 80.28 & 75.73 \\
\hline$\Delta \mathrm{dBA}$ & 0.29 & 0.29 & 0.29 & 0.29 & 0.28 & 0.28 & 0.28 & 0.29 & 0.28 & 0.28 \\
\hline Parameter & \multicolumn{10}{|c|}{ Grosveld } \\
\hline Frequency $(\mathrm{Hz})$ & 63 & 100 & 200 & 400 & 800 & 1000 & 2000 & 4000 & 5000 & 8000 \\
\hline Receiver height (10m) & 80.83 & 85.34 & 88.65 & 87.75 & 83.92 & 82.31 & 76.69 & 70.61 & 68.61 & 64.35 \\
\hline Receiver height $(2 \mathrm{~m})$ & 80.54 & 85.06 & 88.37 & 87.48 & 83.64 & 82.03 & 76.41 & 70.33 & 68.33 & 64.07 \\
\hline$\Delta \mathrm{dBA}$ & 0.29 & 0.28 & 0.28 & 0.27 & 0.28 & 0.28 & 0.28 & 0.28 & 0.28 & 0.28 \\
\hline Parameter & \multicolumn{10}{|c|}{ Lowson } \\
\hline Frequency $(\mathrm{Hz})$ & 63 & 100 & 200 & 400 & 800 & 1000 & 2000 & 4000 & 5000 & 8000 \\
\hline Receiver height (10m) & 96.60 & 98.76 & 98.39 & 93.83 & 86.86 & 84.41 & 76.58 & 68.66 & 66.11 & 60.72 \\
\hline Receiver height ( $2 \mathrm{~m})$ & 96.69 & 98.86 & 98.49 & 93.93 & 86.97 & 84.52 & 76.69 & 68.77 & 66.21 & 60.83 \\
\hline$\Delta \mathrm{dBA}$ & -0.09 & -0.10 & -0.10 & -0.10 & -0.11 & -0.11 & -0.11 & -0.11 & -0.10 & -0.11 \\
\hline
\end{tabular}

\section{CONCLUSIONS}

Numerical computations of Grosveld, BPM and Lowson empirical trailing edge noise models were done for $2 \mathrm{MW}$ wind turbine at different operating and flow conditions. All models are based on scaling laws and utilize boundary layer, geometric data of blade to predict the $1 / 3^{\text {rd }}$ octave band sound pressure levels. The A-weighted sound power level was computed for $2 \mathrm{MW}$ wind turbine using all three models and found to increase with the free stream velocity $(U)$ and rotor RPM by $\sim 2-10 \mathrm{dBA}$ between 
$500 \mathrm{~Hz}$ and $1 \mathrm{kHz}$ in sound spectrum. The results of BPM, Grosveld and Lowson baseline models are in better agreement at midhigh frequency region with existing experiment values obtained for GE1.5sle, Siemens SWT-2.3 MW turbines. A difference of $\sim 7.5 \mathrm{dBA}$ was found for all trailing edge noise models due to boundary layer thickness and displacement thickness effect. Model sensitivity results demonstrated a maximum change of $6 \mathrm{dBA}$ for entire sound spectrum due to increase of rotor speed from 14 to 17 RPM. Most of the noise produced from blade occurred during the downward motion. A maximum difference of $10 \mathrm{dBA}$ due to change in observer position was found between blade azimuth angles of $80^{\circ}$ and $170^{\circ}$, respectively.

\section{AUTHOR'S CONTRIBUTION}

Conceptualization, Bhargava V; Methodology, Bhargava V and Samala R; Investigation, Samala R; Writing - Original Draft, Bhargava V; Writing - Review \& Editing, Samala R; Supervision, Samala R.

\section{FUNDING}

There are no funders to report.

\section{REFERENCES}

Amiet R.K, Schlinker R (1981) Helicopter rotor trailing edge noise. Presented at: 7th Aeronautics Conference; Palo Alto, USA. https://doi. org/10.2514/6.1981-2001

Bastasch M (2011) Summary of international wind turbine noise regulations. Technical Report. Renewable Northwest Project.

Brooks TF, Pope DS, Marcolini MA (1989) Aerofoil self-noise prediction. (RP-1218). NASA Technical Report.

Djikstra P (2015) Rotor noise and aero acoustic optimization of wind turbine aerofoils (Master Thesis). Delft: Technology University Delft.

C Doolan, D J Moreau, L Brooks (2012) Wind turbine noise mechanisms and some concepts for its control. Acoustics Australia 40(1):7-13.

Fink MR (1979) Noise component method for airframe noise. Journal of aircraft 16(10):659-665. https://doi.org/10.2514/3.58586

FW Grosveld (1985) Prediction of broadband noise from horizontal axis wind turbines. Journal of Propulsion and Power 1(4):292-299. https:// doi.org/10.2514/3.22796

Hansen MOL (2008) Aerodynamics of wind turbines. 2nd ed. UK: Earthscan Publishers.

Lee Seunghoon, Lee Seungmin (2013) Numerical modeling of wind turbine aerodynamic noise in time domain. Journal of Acoustical Society of America 133(2):EL94-EL100. https://doi.org/10.1121/1.4774072

Moriarty P, Migliore P (2003) Semi-empirical aeroacoustic noise prediction code for wind turbines. (TP-500-34478). NREL Technical Report. https://doi.org/10.2172/15006098

Oerlemans S, Sijtsma P, López BM (2007) Location and quantification of noise sources on a wind turbine. Journal of Sound and Vibration 229(45):869-883. https://doi.org/10.1016/i.jsv.2006.07.032

Oerlemans S (2011) Wind turbine noise: primary noise sources. (NLR-TP-2011-O66). NLR Technical Report.

O’Neal R, Hellweg Jr. RD, Lampeter RM (2009) A study of low frequency noise and infrasound from wind turbines. Maynard: Epsilon Associates Inc.

Schepers JG, Curvers APWM, Oerlemans S, Braun K, Lutz T, Herrig A, Koegler K (2007) SIROCCO-Silent rotors by acoustic optimization. Presented at: 2nd International Meeting on Wind Turbine Noise; Lyon, France.

Son E, Kim Hyunjung, Kim Hogeon, Choi W, Lee S (2009) Integrated numerical method for the prediction of wind turbine noise and long range sound propagation. Current Applied Physics 10(2):S316-S319. https://doi.org/10.1016/j.cap.2009.11.034

Zhu WJ, Heilskov N, Shen WZ, Sørensen JN (2005) Modeling of aerodynamic generated noise from wind turbines. Journal of Solar Energy Engineering 127(4):517-528. https://doi.org/10.1115/1.2035700

Zidan E, Elnady T, Elsabbagh A (2014) Comparison of Sound Power Prediction Models of Wind Turbines. Presented at: International conference on Advances in Agricultural, Biological \& Environmental Sciences; Dubai, UAE. 